\title{
The Effect of WeChat-Based Online Instruction on EFL Learners' Vocabulary Knowledge
}

\author{
Ehsan Namaziandost $\left(\mathbb{D},{ }^{1}\right.$ Arash Hashemifardnia $\left(\mathbb{D},{ }^{1}\right.$ Albina Anvarovna Bilyalova $\left(\mathbb{D},{ }^{2}\right.$ \\ Doris Fuster-Guillén (D), Jessica Paola Palacios Garay ${ }^{3},{ }^{3}$ Le Thi Ngoc Diep $\mathbb{D}^{\mathrm{D}},{ }^{4}$ \\ Hazhari Ismail $\mathbb{D},{ }^{5}$ Ludmila A. Sundeeva $\mathbb{D}^{6},{ }^{6}$ Hibana $\mathbb{D},{ }^{7}$ and Oriana Rivera-Lozada $\mathbb{D}^{3}$ \\ ${ }^{1}$ Department of English, Shahrekord Branch, Islamic Azad University, Shahrekord, Iran \\ ${ }^{2}$ Naberezhnye Chelny Institute (branch) of Kazan Federal University, Naberezhnye Chelny, Russia \\ ${ }^{3}$ Universidad Nacional Mayor de San Marcos, Lima, Peru \\ ${ }^{4}$ Van Lang University, Ho Chi Minh City, Vietnam \\ ${ }^{5}$ Department in Early Childhood Education, Sultan Idris Education University, Tanjung Malim 35900, Perak, Malaysia \\ ${ }^{6}$ Togliatti State University, Togliatti, Russia \\ ${ }^{7}$ UIN Sunan Kalijaga Yogyakarta, Depok, Indonesia
}

Correspondence should be addressed to Ehsan Namaziandost; e.namazi75@yahoo.com

Received 6 May 2021; Revised 22 June 2021; Accepted 8 July 2021; Published 19 July 2021

Academic Editor: Eddie Denessen

Copyright (C) 2021 Ehsan Namaziandost et al. This is an open access article distributed under the Creative Commons Attribution License, which permits unrestricted use, distribution, and reproduction in any medium, provided the original work is properly cited.

\begin{abstract}
During the COVID-19 pandemic, the use of online instruction through different mobile applications has become more common in education all over the world. Therefore, this research investigated the potential effects of using WeChat-based online instruction on Iranian EFL learners' vocabulary knowledge. To achieve this objective, 44 Iranian intermediate subjects were picked out among 67 students based on the findings of the Oxford Quick Placement Test (OQPT). The subjects were then randomly divided into two equal groups: experimental and control. After assigning the subjects to two groups, they were pretested by a vocabulary test. Then, the experimental group received vocabulary instruction using WeChat application, while the control group received a conventional vocabulary instruction. After the instruction, a vocabulary posttest was given to both groups to assess the effectiveness of the treatment. The gathered data were analyzed through independent samples $t$-test, one-way ANCOVA, and paired samples $t$ test. The outcomes attained in this research demonstrated that there was a significant difference between the posttests of both groups in favor of the experimental group. Eventually, the conclusions and the pedagogical implications of this study were explicated.
\end{abstract}

\section{Introduction}

Integration of technology in education is getting more common, especially during the COVID-19 pandemic. Nowadays, the frequent use of technology and new technological tools can be seen in our daily lives [1]. To do our daily tasks more easily, we apply technology and computers. Technology has integrated into all aspects of our lives, especially our educational system. Technology has affected education and the way the educational process takes place; it also has changed the conventional teaching methods [2].
Technologies are considered the catalyst for enhancing the process of teaching and learning [3].

By applying instructive technology including digital apparatuses, instructors can provide learners with a more pleasant learning situation and more beneficial learning opportunities [4]. Mobile phones and social media are some of the computerized instruments in the present time. Social media refers to the websites and the web-based frameworks accessible by means of any device that empowers people in utilizing the network for mass interaction, discussion, and sharing over the Internet [5]. Teachers are getting more 
fascinated by utilizing social media in their instruction, for example, while educating vocabulary $[6,7]$. In this respect, Ariza and Hancock [8] state that learning vocabulary with the help of social media is very identical to the way a child acquires his first language.

One social application that can be utilized in education is the WeChat application that is a kind of mobile software with social communication attributes and platform function that can suggest a new platform and application mode for distance education [9]. WeChat application is featured with the characteristic of ubiquitous learning, being accessible for almost all learners at any time and from anywhere; it is a mobile text and voice messaging communication service. WeChat learning platform makes distance education more possible, convenient, and effective. Also, it can provide text messaging, hold-to-talk voice messaging, broadcast messaging, video conferencing, video games, sharing of photographs and videos, and location sharing $[9,10]$. To support WeChat, Zeng et al. [11] assert that WeChat can increase students' enthusiasm and interest, boost their self-initiative learning ability, and develop their collaboration with classmates.

Using WeChat application may be an effective tool for developing EFL learners' vocabulary knowledge. According to $\mathrm{Wu}[12]$, vocabulary alludes to the entire words and phrases in a language. Additionally, words are the constructive materials of a language that without them, creating sentences is impossible [13]. When teaching vocabulary, the setting is truly significant that is why Warschauer [14] underlines that the more chances may be presented to genuine communication learners when utilizing the Internet and the e-mail in language learning.

With this study, we aim to contribute to the knowledge of the use of platforms such as WeChat in language learning. With this knowledge, teachers may choose to use such platforms to encourage students to participate more in online tasks to improve their language performance.

Moreover, $\mathrm{Wu}$ and Miller [15] concede the incredible challenges for educators to design or plan different activities utilizing the Internet resources and also acclaim the merits and advantages of the students searching for them. In view of Datzman [16], learning vocabulary makes extraordinary difficulties for instructors and students. Therefore, the researchers hope with this study to contribute to the vocabulary learning assistance of Iranian EFL learners to develop their vocabulary knowledge.

\section{Literature Review}

Technology has been considered a vital improvement because its fast growth covers various aspects of people's lives including education. Nowadays, technology is the centerpiece in educational environments [17-19]. It is believed that technology provides support for teaching and learning in EFL classes. Instructors are currently taking advantage of technological instruments to develop pupils' language skills in EFL contexts. Researchers have discovered that technology can aid learners to be involved in the language learning process. It provides them an opportunity to experience the real world by applying authentic materials and helps teachers hold a more interactive class by utilizing online English exercises. In addition, technology can suggest an active-learning situation for language learners $[15,20]$. For example, some instructors may ask their learners to make a video about performing action verbs, dramatize a short tale, and so on. Moreover, technology can boost favorable attitudes toward learning, saving time for both instructors and pupils [21, 22].

WeChat application as a kind of technological tool is a smart platform that is mostly for people, organizations, or media, and it is combined with subscription, official accounts, and service accounts [23]). Users of WeChat can communicate in groups with photos, messages, and voices. WeChat is an Internet-dependent smart instrument, which has numerous users. This application possesses a capacity that other social applications lack, including timely and accurate information push. Pan et al. [24] characterized WeChat assisted language learning (WALL) as a significant development in the universal learning community. They asserted that WeChat has the capacity to supply a situational and communicative learning situation for learners, which in turn can assist them to change language competence into language proficiency.

WeChat is supported by connectivism that is the learning theory for the digital age [25-28]. Siemens stated that the act of learning is that of making an external network of nodes, where we connect and make up information and knowledge sources. The learning that takes place in our heads is an internal network (neural) [16, 27, 29, 30]. A network includes associations between entities (nodes), where the nodes can be people, groups, systems, fields, opinions, resources, or society $[15,31,32]$. Based on connectivism, learning is a process of connecting specialized nodes or information sources; learning may dwell in nonhuman appliances; protecting and keeping connections are vital to facilitate continuous learning, which stresses the connections and feedback connections [27, 33, 34].

Some experimental studies were conducted on the effectiveness of mobile applications on English language learning. For instance, Basal et al. [35] examined the impacts of a mobile application on teaching idioms to Turkish students. To do this study, the researchers selected 50 firstyear students from an English Language Teaching Department of a state university in Turkey. The participants were divided into two groups: the control group $(n=25)$ and the experimental group $(n=25)$. The participants of the control group were instructed with traditional activities, while the participants of the experimental group were taught using the mobile application. The attained findings demonstrated that the participants of the experimental group outflanked the control group on the posttest.

Shi et al. [36] attempted to solve the problem by introducing mobile-assisted language learning with WeChat instant messaging. To do this study, 50 students were selected as the respondents of this research. After that, the respondents were assigned to two groups. The mobile application of WeChat was used to teach the experimental group, while the other group was taught English without 
using the WeChat application. A pretest and a posttest were given to collect the needed data, and the data were analyzed according to the objectives of the study. The findings revealed that participants who were instructed through WeChat significantly developed more in English proficiency compared with participants who did not use WeChat.

Sung and Poole [37] did a study to examine college students' use of WeChat in a tandem language learning project. They raised two research questions to do this study: (1) How do Chinese-English dyads utilize the WeChat application for weekly language learning? (2) What are the perceptions of the Chinese-English dyads on the use of the WeChat application for language learning? In this exploratory study, the participants' conversations were recorded, and excerpts were utilized to show how the dyads used WeChat application. Also, an online survey was distributed to the subjects after the tandem language learning program finished, which asked questions about how the dyads applied WeChat application for language learning. The findings of the survey recommended that the participants' experiences with WeChat Application were mainly favorable and positive with only a few demerits.

Jin [26] carried out an experimental research based on mobile-assisted language learning and specifically concentrated on the interaction diversity between English teachers and TESOL students. The WeChat application was used in three English reading classes for undergraduate English major students at Shenzhen University, China. The outcomes showed that all the participants stayed online with WeChat all day long and were interested in applying it in English learning. Especially in class, the participants enjoyed taking multistep directions with WeChat, asking for assistance in time, and most importantly, sharing their ideas or reports more willingly than in conventional class.

Lei [38] carried out an experimental research to inspect a useful method for vocabulary learning using the WeChat application on smartphones that were frequently utilized among college students. To carry out this research, 30 students were asked to take part in a WeChat group and were given word tests before and after the research. In addition, a questionnaire survey was conducted a month later. The obtained outcomes demonstrated that it was easy for the participants to accept this novel method of learning and most of them could follow the schedule. They improved their self-regulation study ability and were motivated and inspired to figure out different methods to develop their study via smartphone apps.

Cavin et al. [13] explored the influence of the WeChat application on CFL learners' word learning. The chosen respondents joined the ten-day treatment wherein they applied the three characteristics of WeChat application: WeChat messaging, official accounts, and mini programs. The performances of the participants were determined using tests before and after the intervention. Furthermore, observation checklists were used to identify the change in behavior in learning the vocabulary of CFL learners. The findings showed that WeChat application could develop the learners' vocabulary learning in a foreign language.

Based on the literature reviewed above, using WeChat application is an effective method for learning and teaching the English language. Though this application is useful for teaching and learning and it is known for million learners, studies on WeChat application or WeChat teaching are limited in Iran. Therefore, this study aimed to examine the effects of the WeChat application on developing Iranian EFL learners' vocabulary knowledge. Accordingly, the following research question was posed.

2.1. RQ. Does using WeChat application have an effect on improving Iranian EFL learners' vocabulary knowledge?

\section{Methods}

3.1. Participants. To do this study, a total of 44 (male) intermediate Iranian EFL learners were selected among 67 students using convenience sampling. The participants were between the ages of 15 and 21 years, and their level of English proficiency was determined based on the results of the Oxford Quick Placement Test (OQPT). Due to gender segregation, the researchers selected only male students as their research participants. The selected participants were randomly divided into two groups: one experimental group (EG; WeChat group) and one control group (CG).

3.2. Instruments. The first instrument utilized in the current research was the OQPT to homogenize the participants. It was used to help the researchers determine the level (i.e., elementary, preintermediate, and intermediate) of the participants. According to this test, those students who scored between 30 and 47 (out of 60) were regarded as intermediate learners. As a proficiency test, it is expected to be norm-referenced and is intended to "measure global language abilities" (Brown, 2005, p. 2). OQPT was validated by more than 8,000 students in 25 countries, and its reliability has reached 0.90 .

The second instrument for collecting the needed data to answer the research question of the research was a researcher-made vocabulary pretest. It was designed based on the students' course book (504 Essential Words). This test was administered to evaluate the students' vocabulary knowledge before applying the WeChat treatment. Thirty multiple-choice items were included in this test. The validity of the pretest was approved by a group of English experts, and its reliability was calculated using the KR-21 formula $(r=0.85)$.

The third instrument the researchers used in this research was a researcher-made vocabulary posttest. It was given to the participants to measure the impacts of the treatment on their vocabulary improvement. The posttest was the modified version of the pretest but in the posttest; the order of questions and options were changed to wipe out the probable recall of pretest answers. Since the posttest was the modified version of the pretest and there were only slight differences between them, the posttest was regarded as both reliable and valid. However, the validity of the posttest was approved by those who validated the pretest, and its reliability was calculated using the KR-21 formula $(r=0.98)$. According to Shuttleworth [39], quasi-experimental studies 
usually utilize a pretest-posttest research instrument to help the researchers assess the ability of the participants before and after the treatment.

3.3. Materials. To carry out this research, 93 English words from the book mentioned above were chosen. The selected words include nouns, verbs, adverbs, and adjectives. Then, the researchers gave the list of the words to the participants to check which word was known to them and which one was unknown. The familiar words were excluded from the target words, and the rest were remained to be taught to the participants. According to Dufon and Fong [40], the target words that will be taught would be unknown, unfamiliar, or difficult for the participants. Based on the participants' answers to the word list, 61 vocabulary items were unknown to them, and they were regarded as the materials of the study.

3.4. Data Collection Procedure. When the respondents of the study were homogenized, their level of vocabulary knowledge was gauged by administering a vocabulary pretest. Then, the participants of the experimental group received the word instruction using WeChat application. The participants in the experimental group had WeChat application on their cell phones, tablets, laptops, or computers to use for learning new vocabulary items. In each session, ten words were sent in the WeChat application, and the students were asked to practice them cooperatively. After practicing the words, the respondents were asked some questions on the meaning of the words. When they encountered a problem, they asked the researcher or other participants to help them. The participants in the experimental group were required to make new sentences with the new words.

On the other hand, a traditional method was applied to teach the new words to the participants in the control group. In fact, face-to-face instruction was used to teach the new words to the control participants. The new words were introduced first, and then their translations, antonyms, and synonyms were provided for the students. The entire instruction lasted nine sessions of 40 minutes. In the first and the second sessions, the participants were homogenized and pretested, respectively; in six sessions, the treatment was practiced, and in the last session, the posttest of vocabulary was given to the participants of both groups to determine the impacts of the treatment on their vocabulary development.

3.5. Data Analysis. After gathering the data through preand posttests, the researchers analyzed them based on the objectives of the research. Since the distribution of the data was normal, the researchers decided to apply parametric statistics such as one-way ANCOVA, paired samples $t$-test, and independent samples $t$-test to discover the impacts of WeChat application on Iranian EFL learners' vocabulary knowledge. When all the needed data were gathered, they were analyzed to reach the final results. Before conducting any analyses, the normality of the distribution of pre- and posttest scores for both groups were tested with a
Kolmogorov-Smirnov test. None of the four tests was statistically significant. Therefore, the data were treated as normal, and parametric tests have been performed.

\section{Results}

First of all, to further ascertain the homogeneity of the two groups in terms of their vocabulary knowledge, their pretest scores were compared through an independent samples $t$ test.

Table 1 shows that the EG learners' mean score on the pretest equaled 13.88 and the CG learners' mean score was 13.97. The difference between the mean scores of both groups was not significant $(t(36.42)=-0.19 ; P=0.84)$.

As the main research question of the study was intended to figure out whether using WeChat application could significantly affect the acquisition of vocabulary by Iranian male intermediate EFL learners, the posttest scores of the EG and CG learners had to be compared. To attain this objective, one-way ANCOVA was chosen to be conducted:

In Table 2, it could be found that the posttest mean score of the EG learners $(M=17.93)$ was larger than the posttest mean score of the CG learners $(M=14.38)$. This difference was statistically significant $(F(1,41)=121.53 ; P<0.01)$ as revealed in Table 3 .

The $P$ value here was lower than the alpha level of significance $(0.00<0.05)$, which indicates that the difference between EG and CG on the vocabulary posttest was statistically significant. This means that using the WeChat application could significantly improve the vocabulary learning of the EG learners. Moreover, the effect size value equaled 0.74 , which means that the treatment accounted for $74 \%$ of the difference between the EG and CG learners that could not be explained by the pretest.

\section{Discussion}

The current study explored the effects of the WeChat application on improving Iranian EFL learners' vocabulary knowledge. The findings showed that the experimental group who had received the treatment through WeChat application outflanked the control group who had received the traditional instruction. One reason for the better performance of the experimental group compared with the control group is that WeChat could foster autonomous learning in the experimental group. The other reason is that WeChat assisted them to review class content and share thoughts more efficiently. The other justification for the obtained results is that WeChat is rich in the language material from the Moments threads and posts, which could provide students with a variety of linguistic input to satisfy different interests and needs, and thus stimulate output.

The results of this study proved the effectiveness of using WeChat on developing Iranian EFL learners' vocabulary knowledge. This effectiveness can be attributed to the fact that WeChat is effective to the students' language learning in several ways, including linguistic gain, interactive convenience, feedback immediacy, and especially translation friendly to language learners of elementary level. WeChat 
TABLE 1: Independent samples t-test for the pretest.

\begin{tabular}{lcccccccc}
\hline & Groups & $N$ & Mean & Standard deviation & Standard error mean & $t$ & $\mathrm{~d} f$ \\
\hline \multirow{2}{*}{ Pretest } & EG & 22 & 13.88 & 1.21 & 0.25 & 0.19 & \multirow{2}{*}{36.42} \\
& CG & 22 & 13.97 & 1.83 & 0.39 & 0.84 \\
\hline
\end{tabular}

Note. EG: experimental group and CG: control group.

TABLE 2: Descriptive statistics for comparing the posttest scores of the EG and CG learners.

\begin{tabular}{lccc}
\hline Groups & Mean & Standard deviation & $N$ \\
\hline EG & 17.93 & 0.72 & 22 \\
CG & 14.38 & 2.12 & 22 \\
Total & 16.15 & 2.38 & 44 \\
\hline
\end{tabular}

TABLE 3: Results of one-way ANCOVA for comparing the posttest scores of the EG and CG learners.

\begin{tabular}{lcccccc}
\hline Source & Type III sum of squares & $\mathrm{d} f$ & Mean square & $F$ & $P$ & Partial eta squared \\
\hline Corrected model & 195.47 & 2 & 97.73 & 82.770 & 0.00 & 0.80 \\
Pretest & 57.20 & 1 & 57.20 & 48.44 & 0.00 & 0.54 \\
Groups & 143.51 & 1 & 143.51 & 121.53 & 0.00 & 0.74 \\
Error & 48.41 & 41 & 1.18 & & & \\
Total & $11,733.00$ & 44 & & & \\
\hline
\end{tabular}

created a friendly and comfortable communication setting for the students as well as a platform for the language application.

According to Zou and Li [41], the availability, accessibility, and flexibility of different mobile applications can greatly help English learners increase their motivation for learning. In addition, mobile applications can extend the learning context outside of the classroom environment. As for language learning, the WeChat application is very practical for the learners, since they often do not have adequate time to practice the English language in the classroom context [42].

The WeChat application can enable instantaneous communication for its users, which proves efficient language learning. Teachers can encourage interactions on WeChat. When students post their homework through WeChat in the form of pictures, audio, or text, the teachers can give specific feedback on the performance of the work in different forms to stimulate a comprehensive development in language learning. Furthermore, the teachers could control the group chat and students' moment sharing and respond to their texts and questions within 24 hours [43]. The WeChat application can eliminate time and space restrictions in vocabulary learning and also permits students to review both inside and outside the classroom. Moreover, applying technology can boost EFL learners' motivation, make favorable attitudes toward learning a foreign language [44], and decrease EFL learners' anxiety in language classes [10]. The mentioned advantages for the WeChat application can be the reasons why the experimental group outperformed the control group on the vocabulary posttest.

There are other reasons that may account for the experimental group's better performance in vocabulary learning. First, mobile applications such as WeChat can provide a multimedia learning situation for the students to learn the target words. In the learning section, the students can learn the target words by related photos, comprehensible example sentences, word pronunciation, and Persian meanings. The multimedia presentations assist the students to learn words more easily and prompt their motivation, which gives them the role of "knowledge constructor who actively selects and connects pieces of visual and verbal knowledge" [45]. In addition, utilizing photos and audio files are superior to words alone in developing memory and can aid EFL students to remember the words faster, which is supported by the results of a research carried out by Ramezanali [46].

The second reason refers to the portability, immediacy, and convenience of the mobile applications. The learners could learn and review the new words using the WeChat application both inside and outside the classroom milieu wherever they wanted. These results are in line with Steel's [47] study that discovered that a mobile application for learning language was a more practical aid since it could extend language learning outside the classroom, especially when the in-class language practice time was limited. Furthermore, the mobile applications recommend individualized and private learning; therefore, the students can learn vocabulary at their own pace based on their individual language competence or the speed at which they can memorize words.

The results of this study are in line with Shi et al. [36] who confirmed that the students in the WeChat group significantly improved in English proficiency. Besides, this study is compatible with Jin [26] whose results indicated that all participants stayed online with WeChat all day long and were interested in using it in English learning. Also, the findings of this study are supported by Cavin et al. [13] who examined the effects of the WeChat application on CFL learners' vocabulary acquisition, and their outcomes 
revealed that WeChat could improve students' vocabulary acquisition in a foreign language.

This study supports the theory of connectivism proposed by Siemens [27] who states that learning takes place as the student feeds their knowledge by establishing connections with the collective knowledge of the community [48]. These connections are made in a biological/neural, conceptual, and social/external context [49]. Connectivists held that knowledge is not only transferred from the teachers to the students but also transferred through individuals' interactions and learning does not take place in a single place, especially in a web environment [50]. According to connectivism theory, students are responsible for their learning.

This study also advocates the online collaborative learning theory proposed by Harasim [51], which focuses on the facilities of the Internet to provide learning environments that foster collaboration and knowledge building. Like Siemens [27], Harasim [51] confirms the advantages of teaching and learning through the Internet and large-scale networked education. Based on the online collaborative learning theory, students can collaboratively solve their problems through discourse, and this collaboration can help them develop their English learning.

\section{Conclusions and Implications}

The results showed that WeChat-based instruction assisted Iranian EFL learners to improve their vocabulary knowledge. We can say that WeChat-based instruction can increase the students' interest in learning; also, it can stimulate their motivation to develop their English learning. So, the following conclusions can be drawn:

(1) Teachers need to update their technical knowledge to be able to use new applications successfully. In the age of technology, teachers should learn how to use mobile learning, especially WeChat.

(2) Like teachers, students must develop their technical knowledge to be able to use different applications on their own to learn English at any place and time.

(3) Unquestionably, new technological tools and applications can provide useful opportunities for teaching and learning a foreign language. However, they should not always be considered being superior to classroom instruction. Therefore, the role of teachers in the face-to-face instruction should not be ignored.

The results of this study can bring about some implications for students and teachers. Using WeChat can help shy students reduce their embarrassment in face-to-face interactions; it can decrease their anxiety while speaking English. WeChat instruction as an active learning-teaching method changes a teacher-centered class to a student-centered class. By using WeChat instruction, students can learn actively at any time, both before and after the class. WeChat instruction encourages cooperative group work and incorporates ongoing assessment of conceptual understanding to provide feedback to both students and instructors. A shift from students studying separately to studying in groups for particular questions is beneficial, as individuals are more likely to learn effectively when they work with others than when working alone. In a traditional classroom setting, teachers and students can have communication and interaction only in the classroom but WeChat instruction permits them to have communication even after the class at any time and place. Teachers traditionally use a textbook for an entire semester and use it step by step. By applying WeChat, teachers can keep different materials according to their teaching plan and add updated materials.

\section{Limitations of the Research}

This study has some limitations; only 44 participants were included in this research. This study was conducted on male students, and the female students were not included. The study was limited to Iranian EFL learners; it can be conducted in other countries. The current study was done on Iranian intermediate EFL learners, so its results cannot be generalized to all language learners at different levels in various educational contexts. This research only used preand posttest to advocate the results, which might cast doubts on the robustness of the analysis. Other instruments such as interviews and questionnaires can be used to increase the validity and reliability of the results.

While conducting the present study, some recommendations came across the researchers' mind. The first recommendation for the next studies is to include more participants to get more comprehensible results. The second recommendation for future studies is to work on other language proficiency levels: elementary, upper-intermediate, and advanced. The third suggestion for the next studies with a similar topic is to take gender into account, meaning that both female and male students should be involved. The fourth suggestion is that the next studies are recommended to conduct similar study in other geographical areas. The fifth suggestion is considering the impact of WeChat on other skills and subskills.

\section{Data Availability}

The data that support the findings of this study are available from the corresponding author upon reasonable request.

\section{Conflicts of Interest}

The authors declare that they have no conflicts of interest.

\section{References}

[1] M. Kalogiannakis and S. Papadakis, "Evaluating pre-service kindergarten teachers' intention to adopt and use tablets into teaching practice for natural sciences," International Journal of Mobile Learning and Organisation, vol. 13, no. 1, pp. 113-127, 2019.

[2] S. Papadakis, A. Trampas, A. Barianos, M. Kalogiannakis, and N. Vidakis, "Evaluating the learning process: the "ThimelEdu" educational game case study,"vol. 2, pp. 290-298, in Proceedings of the 12th International Conference on Computer 
Supported Education, vol. 2, , CSEDU, Prague, Czech Republic, May 2020, 978-989-758-417-6.

[3] S. Papadakis, M. Kalogiannakis, and N. Zaranis, "Comparing tablets and PCs in teaching mathematics: an attempt to improve mathematics competence in early childhood education," Preschool and Primary Education, vol. 4, no. 2, pp. 241-253, 2016.

[4] S. Mitra, R. Dangwal, S. Chatterjee, S. Jha, R. Bisht, and P. Kapur, "Acquisition of computing literacy on shared public computers: children and the "hole in the wall'," Australasian Journal of Educational Technology, vol. 21, no. 3, pp. 407-426, 2005.

[5] C. Hill, E. Dean, and J. Murphy, Social Media, Sociality, and Survey Research, John Wiley and Sons Inc, New Jersey, NJ, USA, 2014.

[6] E. Namaziandost, S. Alekasir, M. Hassan Mohammed Sawalmeh, and M. Z. Miftah, "Investigating the Iranian EFL learners' attitudes towards the implementation of e-portfolios in English learning and assessment," Cogent Education, vol. 7, no. 1, Article ID 1856764, 2020.

[7] H. Noor Al-Deen, Social Media in the Classroom, Peter Lang, New York, NY, USA, 2016.

[8] E. N. Ariza and S. Hancock, "Second language acquisition theories as a framework for creating distance learning courses," The International Review of Research in Open and Distributed Learning, vol. 4, no. 2.

[9] W. Shang, "Construction and application of WeChat learning platform in "folk literature" teaching," iJET, vol. 11, no. 5, pp. 10-15, 2016.

[10] M. Rahimi and S. Yadollahi, "Success in learning English as a foreign language as a predictor of computer anxiety," Procedia Computer Science, vol. 3, pp. 175-182, 2011.

[11] F. Zeng, G. Deng, Z. Wang, and L. Liu, "WebChat: a new clinical teaching tool for problem-based learning," International Journal of Medical Education, vol. 7, pp. 119-121, 2016.

[12] Q. Wu, "Learning ESL vocabulary with smartphones," Procedia - Social and Behavioral Sciences, vol. 143, pp. 302-307, 2014.

[13] F. Cavin, G. Donnabelle, T. Nicole, P. Jeniezen, and B. Reggie Mark, "The use of WeChat application on CFL learners' vocabulary acquisition," TESOL International Journal, vol. 13, no. 4, pp. 26-38, 2018.

[14] M. Warschauer, "Comparing face-to-face and electronic discussion in the second language classroom," CALICO Journal, vol. 13, no. 2, pp. 7-26, 1995.

[15] J. G. Wu and L. Miller, "Raising native cultural awareness through WeChat: a case study with Chinese EFL students," Computer Assisted Language Learning, vol. 34, no. 4, pp. 552-582, 2019.

[16] B. Datzman, "Frequency of use, perceived usefulness, and factors affecting second language vocabulary strategies: a study of Japanese learners (Master's thesis)," The Asian EFL Journal, vol. 19, no. 4, 2011, https://www.asian-efl-journal. com/10638/thesis/frequency-of-use-perceived-usefulnessand-factorsaffecting-second-language-vocabulary-strategiesa-study-of-japanese-learners/\#squelch-taas-tabcontent- 0-3.

[17] Z. Abdellatif, "Exploring students' perceptions of using PowerPoint in enhancing their active participation in the EFL classroom action research study," Journal of Literature, Languages and Linguistics, vol. 5, pp. 36-39, 2015.

[18] C. Jia and K. F. T. Hew, "Supporting lower-level processes in EFL listening: the effect on learners' listening proficiency of a dictation program supported by a mobile instant messaging app," Computer Assisted Language Learning, pp. 1-28, 2019.
[19] H. Luo and M. Gui, "Developing an effective ChineseAmerican telecollaborative learning program: an action research study," Computer Assisted Language Learning, pp. 128, 2019.

[20] E. Namaziandost, M. H. Razmi, R. M. Hernández, Y. OcañaFernández, and M. Khabir, "Synchronous CMC text chat versus synchronous CMC voice chat: impacts on EFL learners' oral proficiency and anxiety," Journal of Research on Technology in Education, pp. 1-18, 2021.

[21] J. Schacter, The Impact of Education Technology on Student Achievement: What the Most Current Research Has to Say, Milken Exchange on Education Technology, California, CA, USA, 1999.

[22] S. Xue and D. Churchill, "Educational affordances of mobile social media for language teaching and learning: a Chinese teacher's perspective," Computer Assisted Language Learning, pp. 1-30, 2020.

[23] W. Zhang, L. Fang, and Y. Pan, "On the Application of WeChat platform in the classroom teaching reform," in Proceedings of the International Conference on Education, Management and Computer Science (ICEMC 2016), Shenyang, China, May 2016.

[24] D. Pan, D. Hu, and Z. Quan, "Construction of English listening and speaking community based on language learning SNS-WeChat," College English Teaching and Research, vol. 2, pp. 77-80, 2016.

[25] S. Downe, Connectivism and Connective Knowledge: Essays on Meaning and Learning Networks, National Research Council Canada, Ottawa, Canada, Retrieved from https://www. downes.ca/files/books/Connective_Knowledge-19May2019. pdf, 2012.

[26] L. Jin, "Digital affordances on WeChat: learning Chinese as a second language," Computer Assisted Language Learning, vol. 31, no. 1-2, pp. 27-52, 2018.

[27] G. Siemens, "Connectivism: a learning theory for the digital age," International Journal of Instructional Technology and Distance Learning, vol. 2, no. 1, pp. 3-10, 2005.

[28] L. Skavronskaya, B. Moyle, N. Scott, and V. Schaffer, "Collecting memorable tourism experiences: how do 'WeChat'?" Journal of China Tourism Research, vol. 16, no. 3, pp. 424-446, 2020.

[29] E. Namaziandost, M. H. Razmi, S. Ahmad Tilwani, and A. Pourhosein Gilakjani, "The impact of authentic materials on reading comprehension, motivation, and anxiety among Iranian male EFL learners," Reading \& Writing Quarterly, pp. 1-38, 2021, In press.

[30] Y. Su and X. Xiao, "From WeChat to "We set": exploring the intermedia agenda-setting effects across WeChat public accounts, party newspaper and metropolitan newspapers in China," Chinese Journal of Communication, pp. 1-19, 2020.

[31] F. Bell, Connectivism: A Network Theory for Teaching and Learning in a Connected World, 2009, https://usir.salford.ac. uk/id/\%20eprint/2569/1/ConnectivismEdDev.pdf. Accessed 17 June 2018.

[32] Q. Xu and H. Peng, "Investigating mobile-assisted oral feedback in teaching Chinese as a second language," Computer Assisted Language Learning, vol. 30, no. 3-4, pp. 173182, 2017.

[33] L. Chen, Y. Wang, and C. Rodway, "Social strategy use in online Chinese learning," Computer Assisted Language Learning, pp. 1-28, 2021.

[34] J. Lu, "The WeChat public platform: strengthening HSS academics' global competitiveness in non-English speaking countries (La plataforma pública WeChat: un refuerzo de la 
competitividad global de los académicos de humanidades y de ciencias sociales en países de habla no inglesa)," Culture and Education, vol. 32, no. 3, pp. 609-620, 2020.

[35] A. Basal, S. Yilmaz, A. Tanriverdi, and L. Sari, "Effectiveness of mobile applications in vocabulary teaching," Contemporary Educational Technology, vol. 7, no. 1, pp. 47-59, 2016.

[36] Z. Shi, G. Luo, and L. He, "Mobile-assisted language learning using WeChat instant messaging," International Journal of Emerging Technologies in Learning (iJET), vol. 12, no. 2, pp. 16-27, 2017.

[37] K.-Y. Sung and F. Poole, "Investigating the use of a smartphone social networking application on language learning," The JALT CALL Journal, vol. 13, no. 2, pp. 97-115, 2017.

[38] Z. Lei, "Vocabulary learning assisted with smart phone application," Theory and Practice in Language Studies, vol. 8, no. 11, pp. 1511-1516, 2018.

[39] M. Shuttleworth, Pretest-posttest Designs, Retrieved from https://explorable.com/pretest-posttest-designs, 2009.

[40] P. Dufon and C. H. Fong, "L1 and L2 vocabulary glosses in L2 reading passages: their effectiveness for increasing comprehension and vocabulary knowledge," Journal of Research in Reading, vol. 17, no. 1, pp. 19-28, 1994.

[41] B. Zou and J. Li, "Exploring mobile apps for English language teaching and learning," in Critical CALL-Proceedings of the 2015 EUROCALL Conference, F. Helm, L. Bradley, M. Guarda, and S. Thouësny, Eds., pp. 564-568, Padova, Italy, 2015.

[42] C. Kennedy and M. Levy, "L'italiano al telefonino: using SMS to support beginners' language learning," $\operatorname{Re} C A L L$, vol. 20, no. 3, pp. 315-330, 2008.

[43] X. Huang, "WeChat-based teaching for an immersion cultural exchange program - a case study in CFL. Smart Learn," Environment, vol. 6, no. 7, pp. 1-21, 2019.

[44] A. Q. Yu, Understanding Information Technology Acceptance and Effectiveness in College Students' English Learning in China, Doctoral Dissertation, University of Nebraska, Nebraska, America, 2019.

[45] R. E. Mayer, "Multimedia learning: are we asking the right questions?" Educational Psychologist, vol. 32, no. 1, pp. 1-19, 1997.

[46] N. Ramezanali, "Short and long-term vocabulary learning and retention through multimedia glossing: A mixed methods research," Doctoral Dissertation, University of Western Ontario, Ontario, Canada, 2017.

[47] C. Steel, "Fitting learning into life: language students' perspectives on benefits of using mobile apps," in Proceedings of Ascilite 2012, Future. Challenges Sustainable Future, Wellington, New Zealand, November 2012, Available at: http://www.ascilite.org. $\mathrm{au} /$ conferences/wellington12/2012/images/custom/steel\%2c_ caroline___fitting_learning.pdf.

[48] T. Anderson and J. Dron, "Three generations of distance education pedagogy," International Review of Research in Open and Distance Learning, vol. 12, no. 3, pp. 80-97, 2011.

[49] G. Siemens, "What is the unique idea in Connectivism?," 2008, Retrieved May 21, 2014, from https://www. connectivism.ca/?p=116.

[50] R. Kop, "The challenges to connectivist learning on open online networks: learning experiences during a massive open online course," International Review of Research in Open and Distance Learning, vol. 12, no. 3, pp. 19-38, 2011.

[51] L. Harasim, Learning Theory and Online Technologies, Routledge/Taylor and Francis, New York, NY, USA, 2012. 